\title{
Empresarialismo urbano. Procesos de gentrificación en la Ciudad de México. Entrevista a Luis Alberto Salinas Arreourtua
}

\author{
Laura Solano
}

Invitada nacional

Universidad de Costa Rica

anla.solano@gmail.com

Recibido: 18 de julio 2017

Aceptado: 4 de Agosto del 2017

Laura Solano

Estudiante de la Escuela de Arquitectura de la

Universidad de Costa Rica

\section{Luis Alberto Salinas}

Licenciado, Maestro y Doctor en Geografía por la Universidad Nacional Autónoma de México. Ha realizado diversas estancias de investigación, entre ellas una posdoctoral en el departamento de Ciencia Política y Relaciones Internacionales de la Universidad Autónoma de Madrid, España. Investigador Asociado "C" en el Instituto de Geografía de la UNAM. Miembro del Sistema Nacional de Investigadores, Conacyt, México.

\begin{abstract}
Resumen:
En el marco del Intercambio Académico realizado en la Universidad Nacional Autónoma de México durante el 2016-2017, el investigador Dr. Luis Salinas, del Instituto de Geografía de la UNAM, fue entrevistado por Laura Solano, estudiante del programa Licenciatura en Arquitectura de la Universidad de Costa Rica. La entrevista se llevó a cabo en marzo del 2017 en la UNAM y se enfoca en los procesos de gentrificación en Ciudad México.

Palabras Clave: gentrificación, empresarialismo urbano, Ciudad México, Avenida Chapultepec.

Urban entrepreneurialism. Gentrification processes in Mexico City. Luis Alberto Salinas Arreourtua interview

Abstract:

In the frame of Academic Exchange at the National Autonomous University of Mexico during 2016-2017 period, the researcher Dr. Luis Salinas was interviewed by Laura Solano, student of the Program Licenciatura en Arquitectura of the University of Costa Rica. The interview was held in March 2017 at the UNAM and it focuses on the gentrification processes in Mexico City.
\end{abstract}

Keywords: gentrification, urban entrepreneurialism, Mexico City, Chapultepec Avenue 
Quisiera empezar con la relación que existe entre el urbanismo neoliberal y la gentrificación, en el caso específico de México ¿Cuáles son las particularidades que presenta esta relación?

a gentrificación ha sido un proceso que tiene mucha importancia. Si bien es un concepto que surge en los sesentas (década de 1960) se discute por qué se relaciona con procesos de estructuración neoliberal. Hablar de inversión de capital y de desplazamiento de población ha sido recurrente en la historia de las ciudades; sin embargo, me parece que desde los setentas/ochentas -cuando empiezan las políticas neoliberales-, este proceso se ha agudizado, y hoy en día forma parte de un proyecto de desarrollo urbano, de un proyecto de ciudad.

De las características concretas de México, por ejemplo, podemos hablar de las reformas que se dieron a nivel constitucional, o de reformas políticas diversas, que caracterizan las transformaciones urbanas neoliberales que se están dando en distintas ciudades en México. En el caso particular de la Ciudad de México, antes del 97 no existía ni autonomía ni participación ciudadana; las normativas dependían del Gobierno Federal. En el 82 llega un presidente y se empiezan a implementar políticas neoliberales; la Ciudad de México también se va en esa sintonía. En el 97 hay una reforma y ahí ya se puede elegir un Jefe de Gobierno. Hay una cierta autonomía, y de ahí se pensaba que la CDMX -con el partido que se ha denominado de izquierda- podía generar propuestas diferentes a las implementadas en los últimos años.

Sin embargo, las características del neoliberalismo continúan: entonces los planes de desarrollo urbano están respondiendo a los grandes intereses del capital inmobiliario en general. Muy acorde con lo que hablan muchos autores sobre empresarialismo urbano, hoy en día la forma cómo está gestando y gobernando la Ciudad de México es con una estrecha participación del sector privado en las decisiones del sector público.

Entonces una característica particular de la relación del urbanismo neoliberal y los procesos de gentrificación en la Ciudad de México tiene que ver con las normativas...

Bueno una es la normativa, otra tiene que ver con las instituciones. Una forma particular que se ha discutido sobre gentrificación en América Latina es la gentrificación simbólica. Aquellas transformaciones urbanas que tienen que ver con favorecer la inversión, desplazando población, comercio o actividades que no son bien vistas para la inversión de capital. Por ejemplo, el desalojo de comercio informal -aquí le llaman reubicarhacia espacios que lleguen a ser distantes de los sitios donde ellos se localizan es una forma de higienizar, finalmente desplazar o excluir a un sector de la población, y que está favoreciendo procesos de inversión de capital para la gentrificación. Eso es una particularidad que tiene que ver sí con normativas pero además con una cuestión institucional. Por ejemplo, en la Ciudad de México, en el 2007 se crea una agencia que hoy en día tiene el nombre de ProCDMX, y esta agencia es de participación mayoritaria del gobierno de la ciudad pero la otra parte es de participación privada. Por eso te decía que esa forma de gestión urbana empresarial lo que hace es buscar espacios adecuados en donde podría, a partir de una inversión de capital, a partir de cambios de uso de suelo, tener mayor rentabilidad, y entonces hay campañas previas para estigmatizar ciertos barrios que están en declive o deterioro urbano.

Se podría decir que la Avenida Chapultepec es un ejemplo -no sé si un caso paradigmático- de este tipo de gestión urbana o de entretejido del sector públicoprivado: se puede identificar como una avenida deteriorada que quiere ser mejorada. ¿Cuáles son los factores que han llevado al deterioro de esta avenida y cuáles las consecuencias de esta desvalorización?

Bueno, sí; podría ser un ejemplo como comentas; sin embargo, esta agencia tiene bastantes propuestas que algunas, o muchas de ellas, afortunadamente no se han 


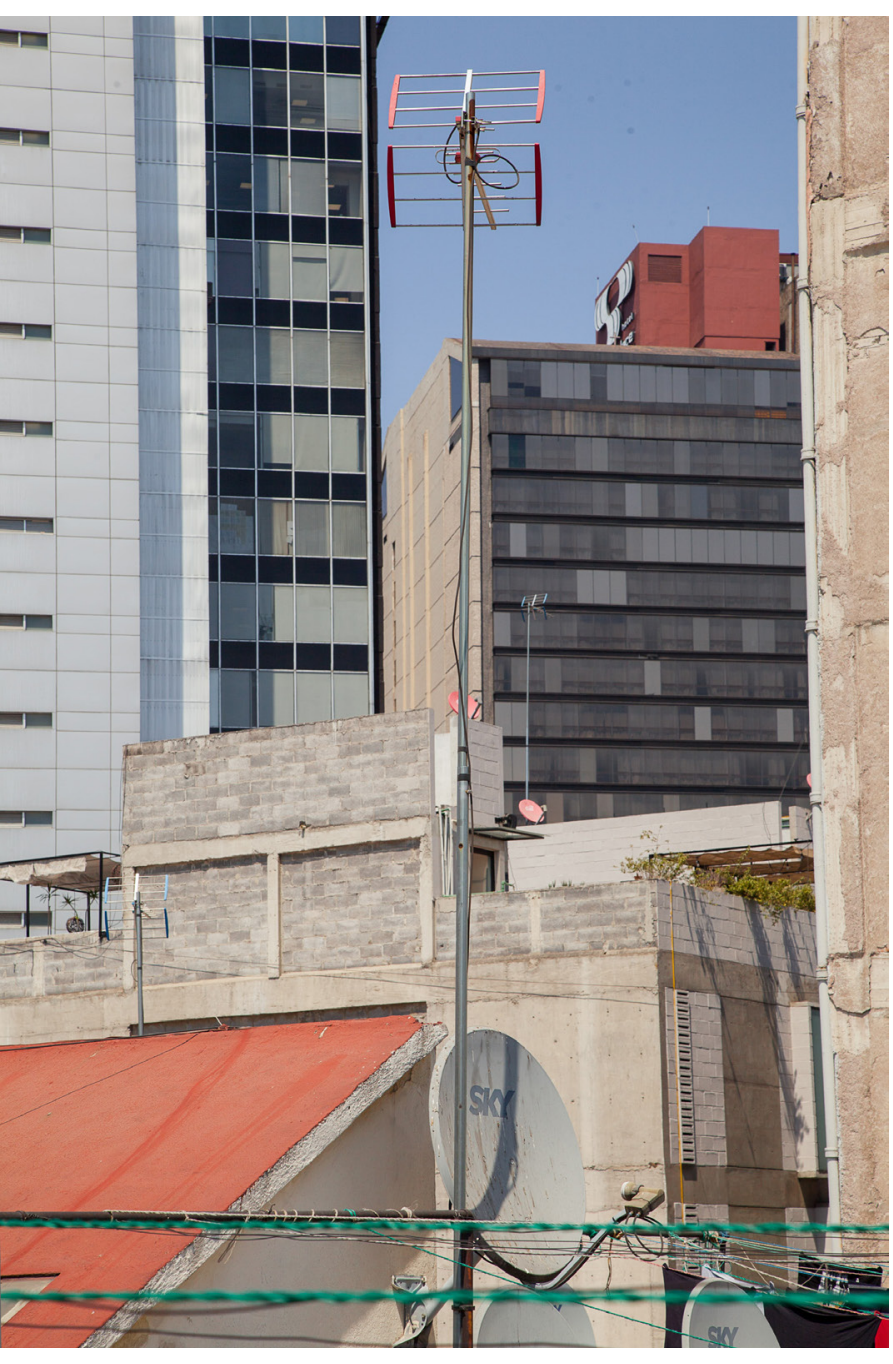

Figura 5. A

Figura 6.

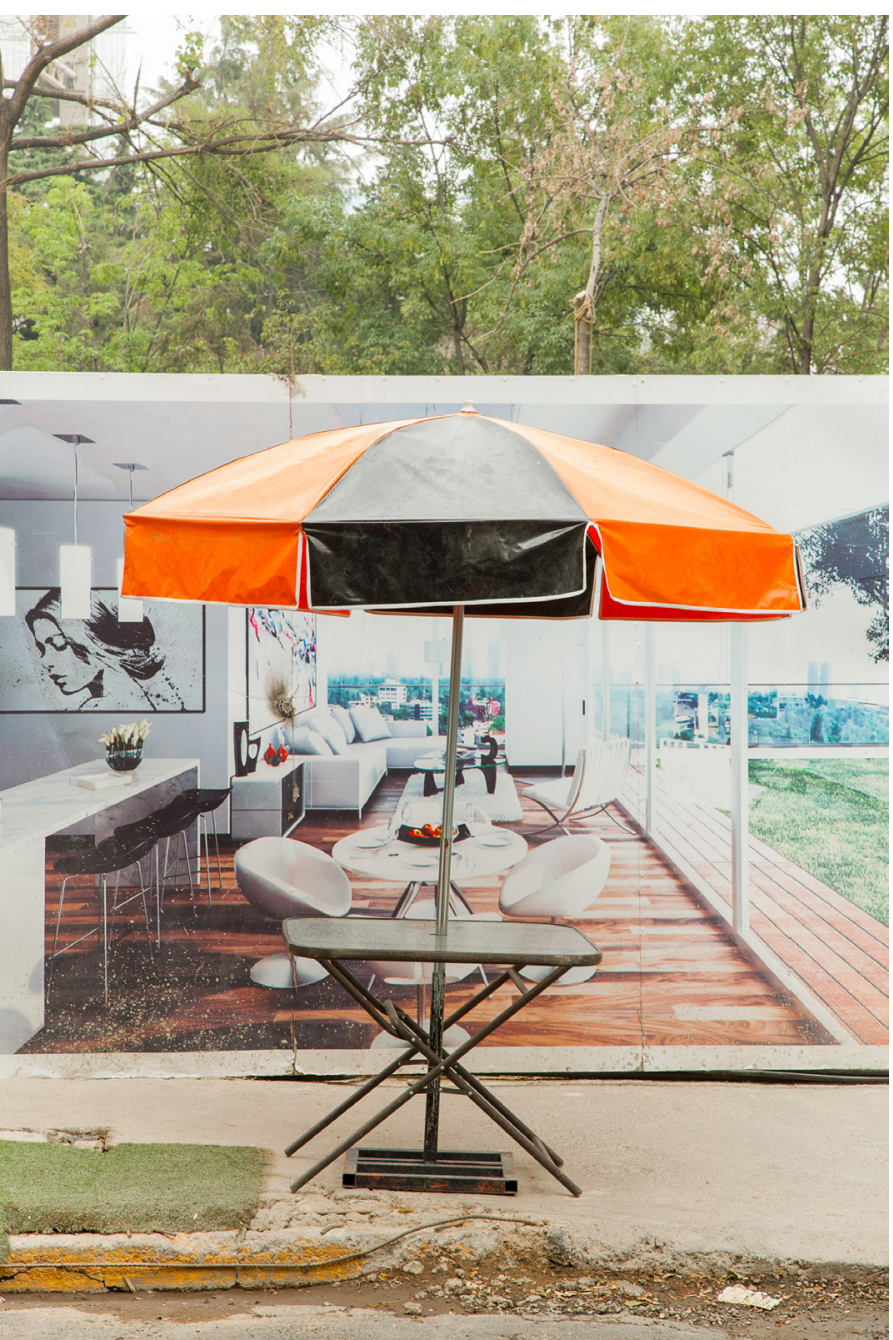

con esa figura jurídica, los derechos adquiridos. Lo que decían es que se construyen expedientes apócrifos y se cambia el uso de suelo. Tanto normativamente, digamos con aspectos legales, lo realizan de manera legal, pero también mediante prácticas de corrupción se realizan todo tipo de transformaciones; entonces esa es una de las formas cómo se están explicando muchas de las transformaciones hoy en día.

¿Qué papel cumplen las imágenes en los procesos de gentrificación? Por ejemplo, hace un tiempo encontré una noticia en un periódico que hablaba de que la gente hace lo que sea por vivir en la Condesa, entonces hay una disposición a pagar rentas muy elevadas a veces en un suelo que es sobrevalorado.

Juegan un papel importante; y, ahorita que lo estás comentando, hay una forma en cómo te están "vendiendo" un barrio: se busca mucho que sientas que tú perteneces primero a un estrato determinado; luego te venden también la idea de la seguridad, que la seguridad es un tema delicado aquí en la Ciudad de México. Muchos de estos desarrollos inmobiliarios te ofrecen esta garantía de que vas a estar en un espacio exclusivo con seguridad las $24 \mathrm{~h}$ del día. De alguna manera lo que se ha buscado es generarte un imaginario y un espacio como si estuvieras aislado de un tejido urbano, con comodidades. Lo que van a hacer es que tú -lo menos posible- puedas salir y todo lo puedas hacer desde tu casa.

Es una forma de excluirte o de venderte un espacio exclusivo dentro de esta conflictividad urbana que existe en la ciudad. Eso por un lado; y por otro, me parece que antes de venderte una idea de comodidad, de seguridad y demás, también existe una estigmatización de los espacios; es decir, la propuesta implica la existencia de un espacio estigmatizado construido anteriormente. Este doble discurso es muy utilizado, tanto por el gobierno, vendiéndote una imagen de peligro, como por el sector inmobiliario.

Una de las características de los procesos de gentrificación es el desplazamiento, pero también lo es la resistencia, ¿Te podrías referir a ambas para el caso de las colonias que has mencionado?

En la Condesa, en la Juárez, en la Roma se han presentado muchos procesos de desplazamiento de varios tipos: hay unos que se puede decir desplazamientos directos o desalojos: llega la seguridad pública de la Ciudad de México y lo que hace es desalojar, sacar a algunos residentes de sus viviendas a la calle y eso se ha dado incluso de forma violenta. Además, queda como una muestra para todos los demás vecinos que no se ajusten tanto a los aumentos de los servicios como a las rentas. Otra forma de desplazamiento es de manera indirecta: se están presentando distintas transformaciones (aumentos de alquileres, aumento de los servicios, la cantidad de comercio está aumentando en esa zona) y esto está mermando las condiciones de esas colonias; entonces alguna de esta gente que tiene los recursos suficientes terminan por hartarse, o terminan por cambiarles lo que es el sentido de barrio que tenían originalmente: entonces se deciden y se van. $Y$ lo otro es el desplazamiento exclusionario, población de las mismas condiciones o de las misma características socioeconómicas a los residentes de esas colonias no pueden hoy en día acceder a una vivienda; si algún hijo de una familia o una familia que se fue de esa colonia por determinada circunstancia quisiera regresar a esta colonia ya no puede por la revalorización o los aumentos de los alquileres.

Las formas de resistencia, en este caso, tienen un capital cultural o económico que les permite, en determinados momentos, tener diferentes formas de actuar. En la colonia Juárez por ejemplo hay incluso iniciativas que pretenden introducir reformas jurídicas; su interlocutor es finalmente gente del gobierno local. Entonces tienen esa posibilidad de dar la pelea no solo en movilizaciones sino también en aspectos jurídicos, en el marco legal. Claro que también están limitados; a pesar de que la gente es de clase media, pueda quejarse y pueda discutir, no implica que sus formas de resistencia necesariamente sean del todo atendidas. 
Aun si hablamos que es un sector medio me parece que es la única forma en la cual se pueden hacer frente a procesos de gentrificación hoy en día en la Ciudad de México. Si me preguntas si hay algunas propuestas alternas, desde el Gobierno de la Ciudad de México no hay ninguna. Y para hacer frente a estos procesos es la organización ciudadana -y eso independientemente si es el sector de bajos recursos, el sector de ingresos medios, como sea-, finalmente es la organización vecinal quienes pueden hacer frente a esos procesos.

Sí; eso en cuanto a hacerle frente, pero me pregunto, ¿qué posibilidades tienen los vecinos de mantenerse resistiendo frente a este desarrollo?

Yo creo que son mínimas. Hoy en día, gran parte de las transformaciones urbanas se deben al sector inmobiliario. Entonces, yo creo que si es estratégica la Avenida Chapultepec, los desarrollos inmobiliarios se van a dar. Me preguntas por cuál es el panorama. Yo creo que es uno negativo, creo que es muy negativo, no creo que haya propuestas diferentes por parte del gobierno local. Pasaba en la Condesa; ellos se resistían a distintas implementaciones por parte del gobierno local, los vecinos se organizaron; resistían, hablaban con el gobierno local y sus propuestas, o sus manifestaciones en contra, eran aceptadas y no se llevaban a cabo. Pero cuando te enfrentas a fuertes intereses de capital inmobiliario, ahí sí de plano no los escuchan.

Entonces, ¿no ves tampoco posibilidades de negociación o de reestructuración de los intereses inmobiliarios en relación con los intereses de los vecinos?

No, no lo veo así, porque incluso eso está pasando ahí en la Colonia Juárez, están comprando predios, viviendas, edificios, porque quieren construir estacionamientos para los desarrollos inmobiliarios que hay; $y$, finalmente, lo están haciendo pese a que hay población que tiene veinte o veinticinco años viviendo. Creo que es parte de la tendencia que tiene la ciudad, están en revalorización todos los ejes centrales y por eso también la zona metropolitana o la periferia de la zona metropolitana está en una expansión de desarrollo de viviendas de interés social. Me parece un proceso que se está llevando a cabo, pero que con el paso del tiempo se va a poder observar de manera más evidente.

De alguna manera, ¿se le podría exigir al sector inmobiliario la permanencia de los habitantes de una colonia?

Sí, por supuesto que ese es el papel del Estado; entonces, el gobierno local tendría que hacer diferentes normativas y decir: bueno, dentro de tu desarrollo inmobiliario por lo menos un porcentaje de viviendas de interés social o que las familias que están ahí se mantengan. Pero justo te decía, yo creo que al gobierno no le interesa eso y lo que está haciendo es favorecer las condiciones para que acumulen capital. Creo que está totalmente en esta gestión empresarialista, que es que el gobierno local favorece todas las condiciones para que la inversión de capital inmobiliario acumule la mayor riqueza.

¿Dentro de las exigencias que pueda dar un grupo de vecinos puede estar la garantía de permanencia de diferentes estratos sociales en el desarrollo inmobiliario?

Claro; yo te hablo de tendencias o de generalidades. Creo que eso que estás comentando tú es muy cierto en el sentido de que se pueden llegar a proponer un proyecto inmobiliario; en algunos casos se podrá dialogar y llegar a algún acuerdo del 
gobierno local, la inmobiliaria y los residentes, y sean casos concretos digamos de cierta participación de los 3 sectores.

En algunos casos creo sí se puede dar porque finalmente también va a depender de las trayectorias y de las formas de organización. Como tendencia general creo que va a existir una imposición por parte del capital inmobiliario y lo que tú me dices creo que se puede dar pero también como casos paradigmáticos.

Es pensar a veces en cómo está actuando el capital inmobiliario; no sé hasta donde. Por ejemplo nosotros le podemos pedir responsabilidad social a una empresa que finalmente su esencia es buscar reproducir su capital; su lógica es: mientras mayores beneficios le lleve a su empresa va a ser mejor. La mayor problemática que existe es que eso es responsabilidad del gobierno y el gobierno no lo está haciendo.

A lo mejor sería conveniente ver cuáles serían las alternativas reales. Entender que hay una realidad, que hay un capital comprometido y que no se trata de mantener los espacios tal cual están; que también hay una lógica que busca invertir capital; que se busca cierto crecimiento económico, pero habría que ver qué medidas se pueden tomar para que esta inversión y este crecimiento no afecte a la población que está afectando en la actualidad.

Bueno, ya para terminar, ¿cómo consideras que la disciplina arquitectónica puede participar en la representación de estas posibilidades?

La división del conocimiento en disciplinas, justo ha generado que las distintas disciplinas tengan enfoques muy limitados que no permiten considerar otros elementos. Para explicar un proceso, los arquitectos en particular, se han enfocado en cómo pueden construir o cómo pueden lograr proyectos que respondan digamos a una lógica. Finalmente, lo que se busca es tal vez los mejores espacios pensando en una ciudad caótica; tal vez dicen: se está expandiendo mucho la ciudad y está teniendo implicaciones ambientales. Entonces, hay que hacer edificios inteligentes o edificios con tales características. Pero, por esa división, creo que hasta ahí quedan. Cuando realmente te das cuenta que ese tipo de proyectos e inversiones, incluso por lo caro que pueden llegar a ser, se van a enfocar para un sector de la población, entonces ya no se considera los efectos o las consecuencias que pueden tener este tipo de desarrollos. No sé qué tipo de formación o qué tipo de discusiones se producen, porque parece que queda así muy en lo estético y funcional; que no va más allá, sin considerar si están haciendo proyectos o edificios para quién o para qué.

Te hacía la pregunta porque frente a estos panoramas, me pregunto si la disciplina se puede centrar en otro objeto que no sea la promoción de edificios con cierta lógica donde no se pregunte exactamente para qué o para quién se diseña.

Bueno, es que eso son retos que se están tejiendo y qué bueno que también desde la arquitectura esos se estén llevando a cabo. 